DOI:10.1515/hssr -2017-0011

\title{
A Global Culture
}

Simona Modreanu*

"Alexandru Ioan Cuza" University of Iasi, Romania

We are currently in a process of passage from one form of consciousness to another. The modern mind is caught in the trap of a mechanical concept about the Universe, which is about to be changed. We have excessively technologized our life, which has increased productivity very much but it has also created damaging dangers. The dizzying and dehumanised speed at which technologies change generates big adjustment problems and deep changes at the level of human psyche, as well as new forms of social organization such as the network. These technologies have a very serious impact on the inner experience of one's personal identity and perception of the self. Man isolates himself and distances himself from nature. Or, identity is also a social construct, and this phenomenological mutation creates problems. Mass-media surround us as a second skin and continuously modify individual frontiers, connectivity networks and moral structures. There is the tendency to unite individual minds, hence numerous mass delusions. We witness accelerations of synchronicities, of intuitions and of the para-psychic and psycho-physic manifestations. Technologic progress allows imagination to make projections of great accuracy and speed by attracting our psyche and our body in an increasingly closer relation.

We need a global culture, a holistic project that should support a sustainable development. This is why we need to bring to life again the transcendentalist impulse that could stir a genuine spiritual revolution in our society. By capitalizing on the social potential of the Internet, which

\footnotetext{
"Faculty of Letters, "Alexandru Ioan Cuza" University of Iasi, 11, Carol I Bvd., 700506, Iasi, Romania; simona.modreanu@gmail.com
} 
is not appropriately understood, we could benefit from a useful infrastructure in order to spread this new paradigm, which could allow, for instance, the harmonious orchestration of resources and policies in a time of crisis.

We have a very strong religion of money; money has become a new golden calf, a postmodern idol that we venerate most of our time. Its very strong fortresses are the banks - one of the most pagan creations, together with stock exchanges. It is not only morality that has been driven away from the economy, from politics and from the entire social life, but the radix itself, the religious root that has undergirded them: "in the sweat of thy face shalt thou eat bread". Work has become demonetised as a social norm and big gains no longer come from work; theft and speculation are encouraged under various ever 'subtle' forms. Globalisation has also become a kind of 'religion' and, in any case, it is the defining problem of the century that we have started, the focal point of some hostile passions and sometimes even of violent protests. A total social phenomenon, globalisation is analogous to nothing from the past and it represents a reality that defies all social and mental paradigms known so far, a gigantic mutation of civilisation that traumatises societies and intimidates intelligences.

It becomes manifest through an increasingly obvious break with the value hierarchies of traditional cultures, as well as with the values of classical western modernity in relation to which it appears as a worrying and non-classifying post-modernity. The state that took the place of the transcendent God is no longer 'born to govern'; it undergoes a devolution of power which is taken over, in part, at subnational level, through the increase of regional and local autonomies and in part at supranational level, through the increase of the role of supranational international organizations that are more or less official. Thus, power is exercised now along several lines. Yet we can say that today power lies in the hands of economy. It tends to be centralized in the hands of big capital and, of course, of its representatives, and it has an esoteric grammar and a Gnostic under-layer.

With the emergence of economy, the equilibrium of late modernity became even more precarious, everybody seems to be fighting against everybody, and we have been at least naive in perceiving the major 
economic stakes of the century and we have lost the battle even before we started by selling almost all our weapons to the enemies. There is an economic totalitarianism just like there is a political totalitarianism. Their pathology is essentially the same; this is why much lucidity and responsibility are required. The problem is that we do not have much of an economy and that we have very few good economists, hence the dependence on the outside and the severe external constraint. We have abandoned our destiny in somebody else's hands. Our individual and collective passions are mainly connected to fortune, which brings about power and pleasure. The 'open society' is full of mercantile spirits that launch severe attacks to the life of the spirit and to the spirit of life. People's appetite for self-destruction seems to have risen exponentially and the order of societies is intensely endangered. Discrepancies in wealth have become so huge that they can ruin the entire social architecture. We see this as a degenerate situation, as man's alienation, as an option for existential closeness towards the transcendent and as a flattering of the ego.

Such a civilisation cannot last. Irrespective of its technological and military endowment, it can only propagate frozen non-values and a mediocre subculture deprived of spirit and of transcendence. In the absence of a religious vertical axis, it can also propagate a lot of destruction. Furthermore, it can even constitute an attack to humans to whom one day we could find a technological substitute, to say nothing of the genetic modifications that flourish. The question is who/what will come after that: the robots, or the yellow race? We need a modified consciousness, and economics, which now dominates, needs moral and spiritual laws in order to become 'Theoeconomics'.

\section{Biographical note}

Simona Modreanu is a $\mathrm{PhD}$ professor of French and Francophone literature at the Faculty of Letters of the "Alexandru Ioan Cuza"University of Iasi. She is also an essayist and a translator, an active member of the CIRET (Centre International de Recherches et Etudes Transdisciplinaire), Paris and co-director of the Transdisciplinary Studies Center of the University of Iasi. She directed the Romanian Cultural Center in Paris (1991-2001) and the Junimea Publishing House in Iasi (2008-2014). Main publications : Eugène Ionesco on l'agonie de la 
HSS, vol. VI, no. 2(2017): 7-10

signifiance (ed. Axis, Iasi, Roumanie, 2002), Le Dieu paradoxal de Cioran (Paris, Ed. du Rocher, 2003), Cioran (Paris, Oxus, 2004), Lecturi nomade (Iasi, Junimea, 2006), Lecturi sedentare (Iasi, Junimea, 2010), Lecturi infidele (Iasi, Junimea, 2014), L'Espace identitaire dans la littérature francophone contemporaine (Iasi, Ed. Univ. "Alexandru Ioan Cuza", 2016). 